\title{
Design Improvement of Coupled IPM Motor-Drive using Physics-Based Motor Model and Evolutionary Approaches
}

\author{
Ali Sarikhani \\ Student Member IEEE \\ Wilder Saint-Hilaire \\ Student Member IEEE \\ Energy Systems Research Lab, Florida International University \\ 10555 West Flagler st., Miami, FL 33172 \\ asari001@fiu.edu,wsain002@fiu.edu,mohammed@fiu.edu
}

O.A.Momammed

Fellow

\begin{abstract}
In this paper, a numerical technique for the magnetic design improvement of a 6 poles-2hp-1200rpm axial flux IPM motor concerning an existing drive circuit is proposed. The design objectives are introduced as the minimum torque ripple, the minimum RMS value of phase currents, and the minimum total harmonic distortion of phase currents. These single objectives together with the current density and magnetic saturation constraints are set to be satisfied at the same time in a multi-objective function. These objectives are calculated from the simulation of the physics-based model of the machine at the same time. The physics-based model of the machine indirectly connects the magnetic characteristics of the IPM machine to the drive circuit. The physical characteristics of machine are calculated from a non-linear transient $\mathrm{FE}$ analysis of machine with motion. A fast convergence rate genetic-particle swarm algorithm is developed and it is used as an optimization tool. The comparisons of the calculated results before and after optimization procedures show the performance improvements as well as material savings.
\end{abstract}

Index Terms - Interior permanent magnet machine (IPM), Physics-based model, Genetic-particle swarm optimization (GAPSO), Coupled motor-drive design, Finite element

\section{INTRODUCTION}

In design process, before prototyping of electrical machines, the computer-aided design of the electromagnetic device such as PM machine either is started from the selection of the initial geometry and material from an existing machine which has generally a near input-output performance to the desired machine, or it is started by calculation of the initial geometry or material from a classics design procedure. Evidently, both of these procedures may not lead to the optimal design that the designer expects to see and therefore the successive change of the design parameters supervised by a skilled engineer team or an artificial intelligent optimization-decision maker algorithm is needed [1]. Evidently, the second method is more desirable because it is less time consuming and less expensive approach to developing new devices or systems. In design solution categories of the PM machines, it is possible to change the back emf waveform of a PM machine by changing the geometrical design parameters of machine or changing the materials. On the other hand, it is recognized that the established current waveform through the machine is mainly proportional to the back emf waveform; therefore in the form of an inverse problem it is possible to change the back emf waveform for having a more desirable current waveform [2]. The current waveform of PM machine plays an essential role in the performance of the machine; firstly, it affects the torque ripple of machine; secondly, it affects the total harmonic distortion of machine; thirdly, it affects the magnetic losses, and, finally it affects the copper losses of machine and therefore consumed copper volume.

On the other hand, the torque ripple of a PM machine is originated from three sources i.e. the cogging torque, the mismatching between current waveform and back emf waveforms, and the mismatching between the phase inductances and the phase currents. In general, there are three possible way to reduce the torque ripple. The first way, is to design the drive of the machine with respect to the maximum compatibility of the phase current to the back emf of machine; The second way is to design the geometry and material of the machine for the minimum cogging torque [3]; and the third way is to design the geometrical design parameter of the machine with respect to the minimum cogging torque and the most compatible back emf waveform to the phase current.

From machine design point of view, the back emf waveform is mainly influenced by magnetic materials, magnets magnetization (radial, parallel, or etc), magnets geometries, and magnets location in the rotor [3]. On the other hand, in geometrical solution category where the cogging torque originates from the energy variation of the air gap field due to the mutual interaction of the rotor magnets and stator openings (slot and teeth openings), there are various techniques to reduce the cogging torque. Basically the main Principles Underlying reduction of the cogging torque is to reduce abruptness of pole-teeth attraction which can be 
performed by magnet reshaping, teeth skewing, pole skewing and etc. [4].

This paper explores the best trade-offs between geometrical design parameters of an IPM motor with the motor phase current, back emf waveform, and cogging torque for a minimum torque ripple, minimum RMS value of phase current, a minimum total harmonic distortion of phase current, and as a result, a maximum efficiency. An optimization algorithm is developed to optimize a multiobjective function which covers the desirable goals. The input variables of the multi-objective function are defined as the normalized variance of torque ripple, RMS value of phase currents and total harmonic distortion of phase currents. The output of multi objective function is a fitness value that is sent to optimization algorithm. An interface block is placed between the multi objective function and optimization block. The interface block consists of a physics-based model of the IPM machine which is used to indirectly link the geometrical design parameters of the machine to the drive circuit and output performances. The inputs of interface block are the geometrical dimension of rotor and stator which mainly affect the magnet and copper volumes and the outputs of this block are the total torque, flux density in a specified location of the machine, current density, and the phase currents. The physics-based model is linked to an existing sinusoidal current drive to account for the effects of the drive topology on the performance of the machine. In fact, the current drive is seen like a black box model while its influences on the performance of the machine are taken into account.

\section{THE PHYSICS-BASED MODELING}

The physics-based model of a PM machines is an accurate, fast, and non-linear dynamic model for the purpose of integrated drive system simulations. In comparison with the $\mathrm{d}-\mathrm{q}$ and the full FE-based models, the physics-based model has the accuracy close to a full FE-based model and it has a simulation run time close to the simple $d-q$ model. This model uses non-linear transient finite elements (FE) solutions to establish a detailed block description of the implemented machines in a Simulink environment. This model accounts for flux weakening as well as other performances [5]. This model is essentially a database representation of the nonlinear transient operation of the machine. The physics-based model can be simply and quickly recreated when the machine geometry and material is changing during an optimization process.

The creation of the physics-based model consists of two general steps. In the first step, a non-linear transient finite element analysis is done to calculate the cogging torque, back emf, flux linkage, and the inductance Matrix of the machine.

The physics-based model is rotor-position dependent, therefore all of the finite element analysis must take the transient analysis and the motion of rotor into account. The rotor-position dependence of the back emf, the cogging torque, the inductances, and the flux linkages are shown in
Figures 3 to 6 respectively. The back emf, and flux linkage, and Inductances are solved for rotation position with the speed equal to the nominal speed. The cogging torque is calculated for each mechanical degree of the rotation with one complete revolution. The inductance matrix is calculated by the incremental method [6] In FE domain, the corresponding magnetic vector potential for a rotating machine is calculated as:

$-\nabla \cdot\left(\sigma \frac{\partial A}{\partial t}-\sigma \vartheta \times(\nabla \times A)-J^{e}\right)=0$
$\sigma \frac{\partial A}{\partial t}+\nabla \times\left(\mu^{-1} \nabla \times A-M\right)-\sigma \vartheta \times(\nabla \times A)=J^{e}$

Where $\sigma$ is the conductivity, $A$ is the vector potential, $\vartheta$ is the Velocity of the modeled object, $J^{e}$ is the external current Density, $\mu$ is the permeability, and $M$ is the magnetisation. The constitutive relation considering ferromagnetic saturation is:

$B=\mu_{0}(H+M)$

Where $B$ is the flux density, $H$ is the field strength, and $\mu_{0}$ is the permeability of air.

In the second step, after the FE analysis, the FE domain solutions are collected into lookup tables in the Simulink environment, and then, the machine electromechanical equations, equations (4) - (8), are implemented in the same Simulink domain. Following the implementation of the phase variable model in Simulink, a PWM drive with IGBT switch and a speed controller were used in parallel with the phase variable model of the machine to control the speed as given in figure 1 (b).

To achieve high simulation accuracy in the FE domain, an attention is given to the rotating air gap mesh and the timestep of the transient analysis. Nodes on the lateral dimension of the rotating air gap are evenly spread. The time-step of transient analysis is the same as the time required for moving the radial angle between two contingent nodes. Moreover, due to simulation time restrictions, it is not possible to increase the number of meshing from a certain value in the FE domain therefore some numerical spikes may be presented in the waveforms of the back emf and inductances. In order to eliminate these spikes, a wavelet filtering technique [7] is used to filter out these numerical spikes.

Following the implementation of the physics-based model of the machine in Simulink, a sinusoidal current drive was linked to the implemented model of the machine to control the speed, see Figure 1(a,b). The drive circuit is a hysteresis modulation sinusoidal current control [8] with hysteresis band equal to 0.3 Amps.

$$
\begin{aligned}
& V_{a b c}=R_{a b c} i_{a b c}+d \varphi_{a b c}\left(i_{a b c}, \theta\right) / d t \\
& \varphi_{a b c}\left(i_{a b c}, \theta\right)=\varphi_{s a b c}(\theta)+\varphi_{r a b c}(\theta) \\
& =L_{a b c}(\theta) i_{a b c}+\varphi_{r a b c}(\theta) \\
& T_{M}=\left[p\left(0.5 i_{a b c}^{T} d L_{a b c}(\theta) / d \theta\right) \cdot i_{a b c}\right. \\
& \left.+i_{a b c}^{T} d \varphi_{r a b c}(\theta) / d \theta\right]+T_{c o g}(\theta)
\end{aligned}
$$




$$
\begin{aligned}
\frac{J d \omega}{d t} & =T_{m}-F \omega-T_{L} \\
\omega & =d \theta / d t
\end{aligned}
$$

In the above equations, the flux linkage $\varphi_{a b c}$ is composed of two parts, as shown in Eq. (5). The first part is related to the inductance $L_{a b c}$ of the stator winding, while the other part is contributed by the permanent magnets on the rotor, represented by $\varphi_{a b c}$. $V_{a b c}, R_{a b c}$, and $i_{a b c}$ are the terminal voltage, resistance and current of the stator winding, respectively. The cogging torque $T_{\operatorname{cog}}$ is added to obtain the total output torque $T_{m}$, as shown in Eq. (6). The rotation angle/rotor position is represented by $\theta$. Here $L_{a b c}, \varphi_{a b c}$ and $T_{c o g}$ are measured as rotor-position-dependent parameters. Also, in these equations $p, J, \omega$ and $F$ are the number of pole pairs, inertia, angular speed, and friction factor, respectively. The load torque is $T_{L}$.

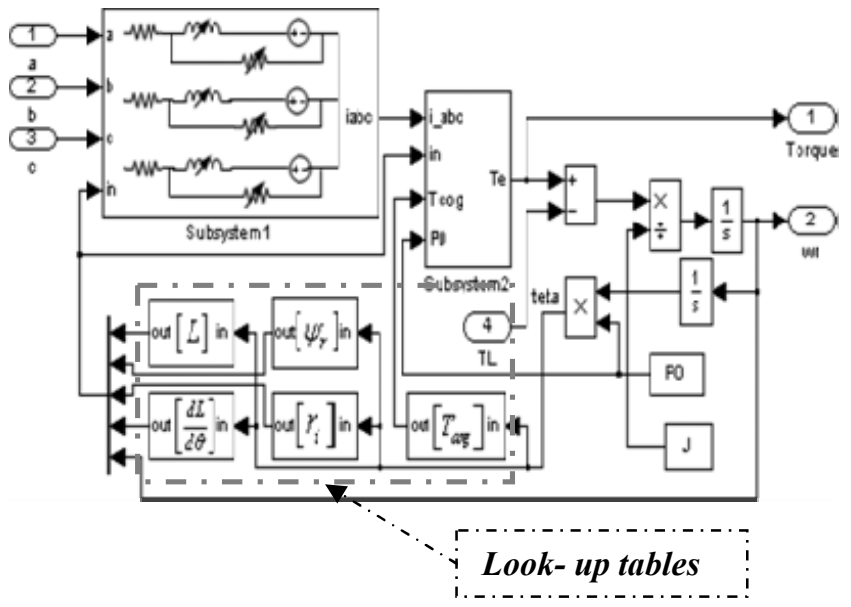

Fig. 1(a): Physics-based model of IPM machine [5]

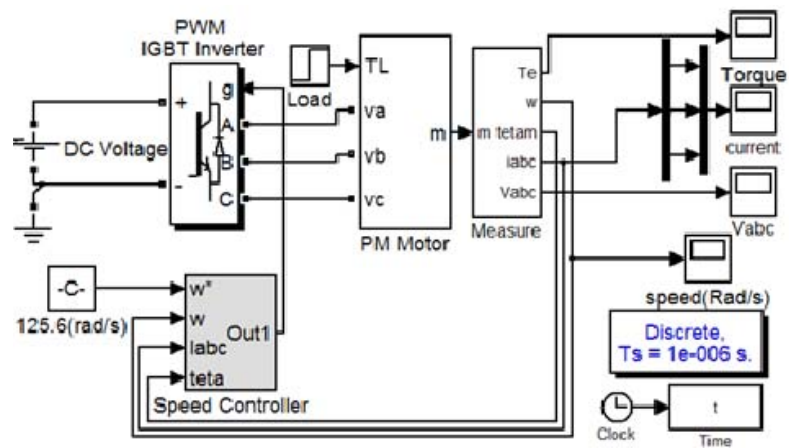

Fig. 1(b): Physics-based model of the machine connected to the PWM IGBT drive and speed controller

\section{OPTIMIZATION PROCESS}

A. The Hybrid GA-PSO

Particle swarm optimization (PSO) is a population-based optimization algorithm that explore for the best solution by simulating the movement and flocking of birds [9]. The Particle swarm optimization (PSO) is launched by initializing of $N$ set of $n$-dimensional flock of birds randomly over the $n$ - dimensional searching space. For a $n$-dimensional search space, the $i^{\text {th }}$ particle, can be represented by a $n$-dimensional vector, $X_{i}=\left[x_{i 1}, x_{i 2}, \ldots, x_{i n}\right]^{T}$, and velocity $V_{i}=\left[v_{i 1}, v_{i 2}, \ldots, v_{i n}\right]^{T}$. Therefore the total size of each population is an $\mathrm{n}$ by $\mathrm{N}$ matrix.

In PSO, the best position that the particle $i$ visited so far, referred to as $P_{i}=\left[p_{i l}, p_{i 2}, \ldots, p_{i n}\right]^{T}$, and the best position of the best particle in the swarm is referred as $G=\left[g_{l}, g_{2}, \ldots, g_{n}\right]^{T}$. Each particle $i$ can adjusts its position in next iteration $t+1$ with respect to Equations (9) and (10) [10]:

$$
\begin{gathered}
V_{i}(t+1)=\omega(t) V_{i}(t)+C_{1} r_{1}\left(P_{i}(t)-X_{i}(t)\right) \\
+C_{2} r_{2}(G(t)-x(t)) \\
X_{i}(t+1)=X_{i}(t)+\chi V_{i}(t+1)
\end{gathered}
$$

Where $\omega(t)$ is the inertia coefficient which is employed to control the effect of the previous history of velocities on the current velocity. $\chi$ is a constriction factor which is used to limit velocity. Here, $\chi$ is equaled $0.71 . C_{1}$ and $C_{2}$ denote the cognitive and social parameters and $r_{1}$ and $r_{2}$ are random real numbers drawn from uniformly distributed interval $[0,1]$. $\omega(t)$ is initialized it to a large value (here 1), giving priority to global exploration of search space, and gradually decreasing to a small value about zero (here, 0 ) as to obtain refined solution [6]. $C_{1}$ and $C_{2}$ adjust dynamically [11]. Experiments indicate to initialize $C_{l}$ to 2.5 and decrease it monotonically to 1.5 during optimization procedure. For enhancing the PSO's ability in escaping from local minima, a mutation operator is mixed to the PSO algorithm $[12,13]$. In this study, mutation probabilities for iteration intervals of $[4,10]$ is five percent. After several simulations, it was seen that algorithm converges for up to six iterations. Consequently, the maximum number of iterations is set to 10 . Different simulation shows that the algorithm is converged after 130000 second. The used CPU and memory are $1.17 \mathrm{~GB}$ and $3 \mathrm{GHz}$ respectively. At the end of each of the iterations, a reselection is also done based upon selection probability of each solution, Eq. 18.

\section{B. Multi-Objective Optimization}

A classical move toward a multi-objective optimization problem is to allocate a weight $\omega_{i}$ to each Normalized objective function $Y^{\prime}(x)$ so that the optimization problem is appear in term of a single objective problem with a scalar objective function as [14]:

$$
\min (Y)=\omega_{1} Y^{\prime}{ }_{1}(X)+\omega_{2} Y^{\prime}{ }_{2}(X)+\cdots+\omega_{k} Y^{\prime}{ }_{k}(X)+\text { Penalti }
$$

Where $Y_{k}{ }^{\prime}(x)$ is the normalized objective function of $Y_{k}(x)$, and $\sum \omega_{i}=1$. This method is called the priori method since the user is expected to offer the weights. Solving a problem with the objective function (Eq. 11) for a given weight vector $w=\{w 1, w 2 \ldots w k\}$ yields a single solution, and if multiple solutions are desired, the problem must be solved multiple times with different weight combinations randomly. The main difficulty with this method is selecting a weight vector 
for each run [14]. The random calculation of weights is provided in step 2.2. The steps for atomizing the whole of the optimization process is summarize as below:

Step 1: Generate " $i$ " sets of random variables as the inputs of optimization process with respect to the initial geometry calculated from the classic design of the machine and their boundaries like: $X_{\text {in }}=\left[x_{i 1}, x_{i 2}, \ldots, x_{i n}\right]$

Step 2: Assign a fitness value to each solution by performing the following steps:

Step 2.1: Generate a random number $u_{k}$ in $[0,1]$ for each objective indices " $k$ ".

Step 2.2: Calculate the random weight of each objective " $k$ " as:

$\omega_{k}=\left(\frac{u_{k}}{\sum_{i=1}^{k} u_{i}}\right)$

Here two random numbers are generated between zero and one, then, based upon those two random numbers the three weights for torque ripple, THD, and RMS value of phase currents are calculated as:

$\omega_{1}=\left(\frac{u_{1}}{1+u_{2}}\right), \omega_{2}=\left(\frac{1-u_{1}}{1+u_{2}}\right), \omega_{2}=\left(\frac{u_{2}}{1+u_{2}}\right)$

Step 2.3: Calculate the fitness value as:

$\left(X_{i}\right)=\sum_{k=1}^{K} \omega_{k} Y_{k}\left(X_{\text {in }}\right)+$ penalti $\left(J_{\max }\right)+$ penalti $\left(B_{\max }\right)$

Where the penalties are defined as:

penalti $\left(J_{\max }\right)=3\left(\left(I_{R M S}[A] / \text { Conducror area }\right)-5\right)^{3}$

penalti $\left(B_{\max }\right)=\left(B_{\max }[T]-1.3[T]\right)^{5}$

Here, the constraint of the $B_{\max }$ is calculated for when the stator is exited, however the field in a PM machines is mostly dominated by the magnets rather than armature coils.

Here $Y_{1}, Y_{2}$ and $Y_{3}$ are normalized variance of torque ripple, Equation (14), normalized total harmonic distortion of phase current, Equation (15), RMS of phase current, Equation (16), penalti $\left(J_{\max }\right)$ is the penalty factor of maximum allowable current density, and penalti $\left(B_{\max }\right)$ is the penalty factor of maximum allowable flux density respectively. In this work, the motor constant function, Equation 18, as an indication of the cost of producing the average torque is served as a criterion for comparison between the initial and optimal design.

$\operatorname{Var}(T)=\sum_{i=1}^{m}\left(T_{e i}-\overline{T_{e}}\right)^{2}, \quad m=1,2, \ldots,{ }^{t_{\text {top }}} / \mathrm{t}_{\text {step }}+1$

$T H D=\frac{I_{H}}{I_{a}}, I_{H}=\sqrt{I_{3}{ }^{2}+I_{5}{ }^{2}+\cdots+I_{2 n-1}{ }^{2}}, \quad I_{a}=R M S\left(I_{1}\right)$

$I_{R M S}=\sqrt{I_{1}{ }^{2}+I_{3}{ }^{2}+\cdots+I_{2 n-1}{ }^{2}}$

$K_{m}=\frac{\left.\overline{\left(T_{e}\right.} / 3\right)}{\sqrt{I_{R M S A}^{2} R_{a}}}$

In Equations 14 to $17, T_{e i}$ is the instantaneous torque, $\overline{T_{e}}$, is the average toque, $I_{R M S A}$, is the $R M S$ value of current in phase $A$, and $T H D$ is the total harmonic distortion of current.

Step 3: Calculate the selection probability of each solution as:
$p(x)=\left(\frac{\left(f\left(X_{i}\right)-f^{\min }\right)}{\sum\left(f\left(X_{i}\right)-f^{\min }\right)}\right)$

Where, $f^{\min }$ is the minimum value of multi-objective function in each of the iterations.

Step 4: do the proposed Genetic-particle swarm optimization.

Step 5: If the stopping condition is not satisfied, go to Step 2. Otherwise, return to populations and objective values.

\section{C. $\quad$ The discrete search space}

Because the FE-based calculations of the physical characteristics of the IPM machine are a time consuming, and the optimization is an iterative task, it is necessary to limit search space. Here, the search space is limited by rounding the value of random variable $X_{i n}=\left[x_{i 1}, x_{i 2}, \ldots, x_{i n}\right]$ as:

$x_{i k \text { new }}=$ round $\left(\frac{m \times x_{i k}}{x_{i k \max }-x_{i k \min }}\right) \times \frac{x_{i k \max }-x_{i k \min }}{m}$

Where $x_{i k \max }$ and $x_{i k \min }$ are the limitation of variables which are listed in table 3 , and $2 \leq m \leq \infty$ is the space reducer factor. In fact by using equation (19) the continuous search space is divided into $m$ discrete search space. A proper choice of " $m$ " depends on the accuracy of manufacturing, time restriction for simulation, and physic of problem. Here " $m$ " is fixed to ten. The whole optimization process is shown in figure 2.

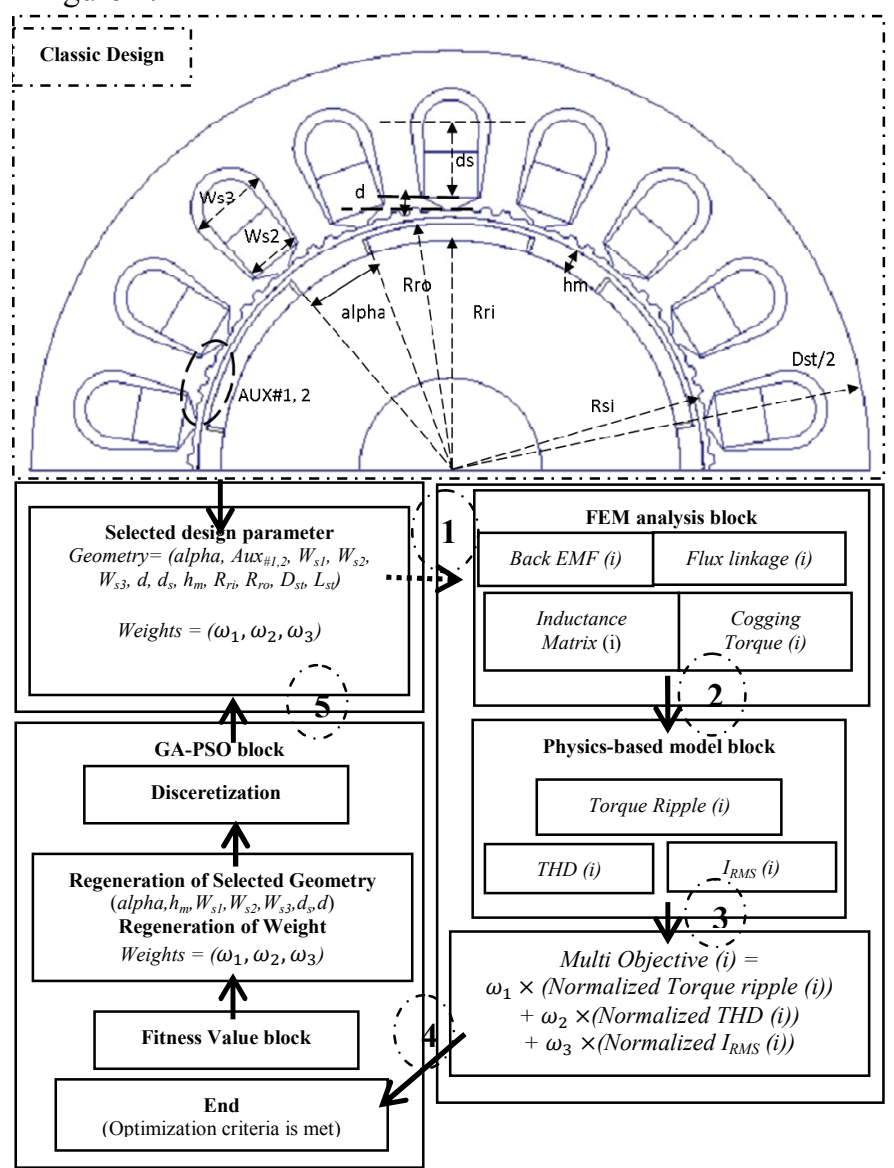

Fig. 2: Schematic view of the multi-objective field-performance optimization 


\section{Classic Design OF IPM MACHINE}

A 36-slot, 2-hp IPM synchronous machine is designed [3]. The rated speed of the PM machine is $1200 \mathrm{rpm}$. This machine has a three phase, and six magnet poles. The preferred magnet material is Samarium Cobalt, Sm2Co17, with permanence of magnets, $\mathrm{Br}$, equal to $1.08[\mathrm{~T}]$, with relative permeability, $\mu_{R}$, equal to 1.07. Coercively of magnet, $\mathrm{Hc}$, equals to $900 \mathrm{KA} / \mathrm{m}$; the saturated flux density

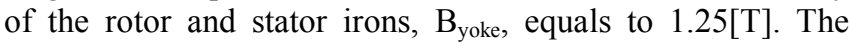
motor is designed for a current density equal to three $\left(\frac{\mathrm{A}}{\mathrm{mm}^{2}}\right)$, conductor space factor equals to 0.65 , and average flux density of air gap equals to $0.56[\mathrm{~T}]$; the inter-pole angle equals to zero. The detail of the initial stator and rotor geometries are listed in tables II, III, and IV.

In this paper it was assumed as the pole width decrease, i.e. inter pole angle is increased then the pole height is increased proportional to that. Different relationship between pole height and pole width was tested and finally it was seen that the best relationship between these two can be stated as the form of:

$\mathrm{hm}_{1 \text { new }}=\mathrm{hm}_{0}\left(1+\log \left(\frac{\mathrm{hm}_{1 \text { pre }}}{\mathrm{hm}_{0}}\right)\right)$

Where, $\mathrm{h}_{\mathrm{m} 0}$ and $\mathrm{hm}_{1 \text { pre }}$ are calculated as:

$\mathrm{hm}_{0}=\mathrm{R}_{\mathrm{ro}}-\sqrt{\left(\mathrm{R}_{\mathrm{ro}}^{2}-\left(\mathrm{p} \times \mathrm{A}_{\mathrm{mag}} / \pi\right)\right.}$

$\mathrm{hm}_{1 \text { pre }}=\mathrm{R}_{\text {ro }}-\sqrt{\mathrm{R}_{\text {ro }}^{2}-\left(\mathrm{A}_{\mathrm{mag}} /\left(\frac{\pi}{\mathrm{p}}-\frac{\mathrm{p} \alpha}{360}\right)\right)}$

In above equation, $A_{\text {mag }}$, is the initial designed area of magnet, $R_{\text {ro }}$ is the outer diameter of rotor, $p$ is the number of poles, and $\alpha$ is the inter-pole angle in degree.

In the optimization process, the candidate design parameters of the IPM machine are the pole heights, $h_{m}$, stack length, $L_{s t}$, and inter-pole angles, $\alpha$, which basically change the magnet poles volume and lower slot width $W_{s 2}$, upper slot width $W_{s 3}$, and slot height $d_{s}$ which basically change the copper volume in each slot. Auxiliary teeth, Aux. \#1 and Aux. \#2, are placed for having more flexibility in the design, see Table I. It can be said that the variables can change the magnets, and the copper areas, consequently, the Ohmic loss and cost of machine can be changed although in this work this objectives are not considered directly. In this work, the outer radius of rotor and stator are not the interested design parameter. A series of floating points which assimilate the design parameter of machine are used as the input variables of optimization problem. Moreover, the machine geometries are allowed to change in two directions, i.e. in radial direction and in the length direction. Here, the relationships between the dimensions change in the stack length direction and in the radius direction are respectively expressed as:

$L_{\text {st_New }}=C_{f} \times L_{\text {st_old }}$

$$
R_{\text {New }}=R_{\text {Old }} / \sqrt{C_{f}}
$$

TABLE I

BOUNDARIES OF OPTIMIZATION INPUT VARIABLES

\begin{tabular}{cccccc}
\hline $\begin{array}{c}\text { Radial } \\
\text { height of } \\
\text { Aux.\#1 }(\mathrm{mm})\end{array}$ & $\begin{array}{c}\text { Radial } \\
\text { height of } \\
\text { Aux.\#2 } \\
(\mathrm{mm})\end{array}$ & $\begin{array}{c}\text { Inter-pole } \\
\text { angle } \\
(\text { degree })\end{array}$ & $\begin{array}{c}\text { Pole } \\
\text { height }\left(\mathrm{h}_{\mathrm{m}}\right) \\
(\mathrm{mm})\end{array}$ & $B_{\text {yoke }}[\mathrm{T}]$ & $C_{f}$ \\
\hline$[0,0.5]$ & {$[0,2.4]$} & {$[0,10]$} & {$[2.8,4.5]$} & {$[0,1.3]$} & {$[0.9,1.1]$} \\
\hline$W_{s 2}(\mathrm{~mm})$ & $W_{s 3}(\mathrm{~mm})$ & $d_{s}(\mathrm{~mm})$ & $\left.J\left(\mathrm{~A} / \mathrm{mm}^{2}\right)\right)$ & $L_{s t}(\mathrm{~mm})$ & $\bar{T}_{e}(\mathrm{n} . \mathrm{m})$ \\
\hline$[5.5-6.5]$ & {$[7-8.5]$} & {$[18-20]$} & {$[2,5]$} & {$[65-85]$} & 11 \\
\hline
\end{tabular}

\section{SIMULATION RESULTS}

Figure 3 shows a comparison between initial and optimized back emf waveforms, it is seen that the optimized machine prefer to have a more smooth back emf waveform specially on the top of waveform. The back emf of the original motor is the summation of a trapezoidal waveform and a dominant sine wave. The frequency that dominant sine wave is five times of fundamental frequency of back emf waveform. The back emf waveform of the optimized machine is a semisinusoidal waveform with improved area and a dominant half cycle sine waves with respective frequencies nine times of fundamental frequency of semi-sinusoidal back emf waveform.

Figure 4 shows a comparison between the cogging torques before and after optimization. The optimized machine has a cogging torque at least four times lower than the cogging torque of the initial design and the frequency of the cogging torque is increased twice.

Figure 5 shows the self and mutual inductances before and after optimization. As can be seen from this picture, the absolute amplitude values of both self and mutual inductances is increased that is more desirable to the current dive.

Figure 6 shows the flux linkage of the machine before and after optimization. It is seen that the maximum value of the flux linkage is increased that will help the machine to be supplied by a lower current.

Figure 7 shows the total torque of the machines before and after optimization. As it is illustrated in this Figure, the torques ripple of optimized machine is decreased at least four times in comparison with the torque ripple of the initial design. A part of this ripple reduction is because of reduced cogging torque and a part of that is because of minimization of mismatching between the current and back emf waveforms. The comparison between the phase of self and mutual inductance in one phase before and after optimization shows that after optimization, a phase shift is occurred in the inductances that mainly will cause to a developed reluctance torque in the machine, due to the change of the rotor shape and its material in the vicinity of the air gap after optimization.

Figure 8 shows the simulated speed of original and optimized machines. It is seen that the optimized machine has 
a small overshoot at the start up. The enlarged view of speed shows that speed ripple of the optimized machine is reduced, although it was not a direct objective.

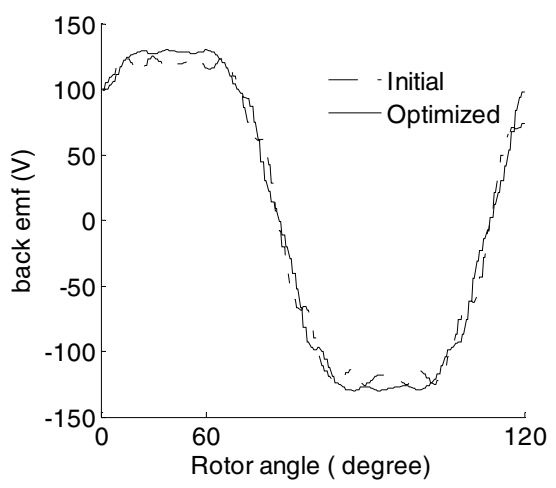

Fig.3: Back emf of the phase $A$ before and after optimization

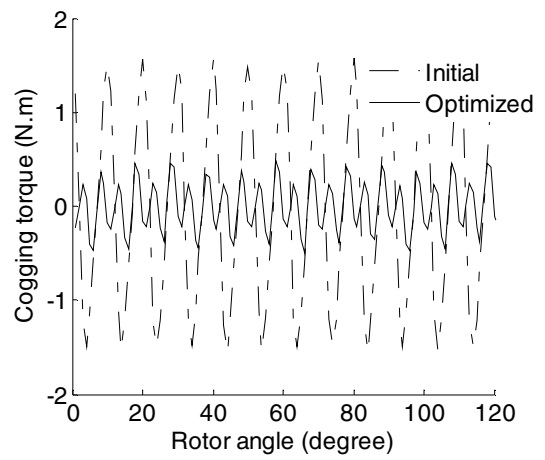

Fig. 4: The cogging torque in initial and optimized design

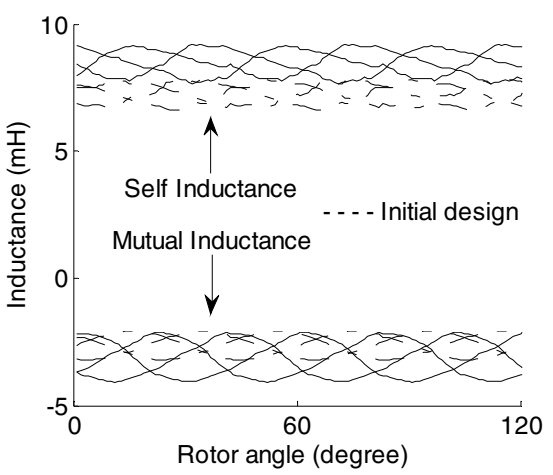

Fig. 5 : Self and mutual inductances before and after optimization

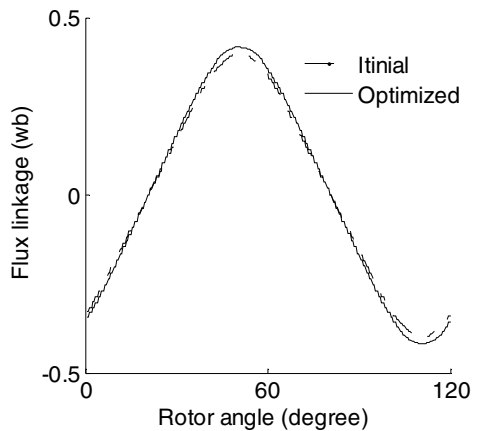

Fig. 6 : Flux linkage of the phase $A$ before and after optimization

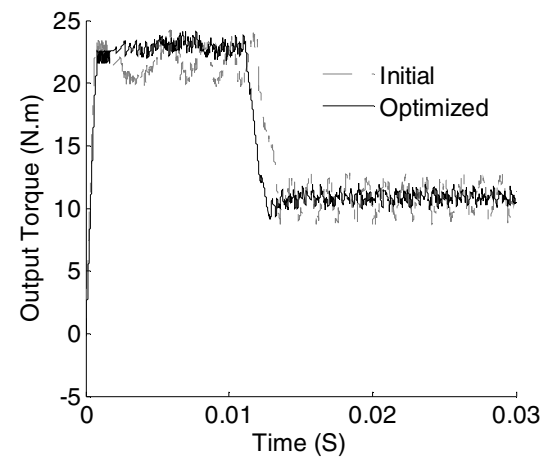

Fig. 7: Total torque before and after optimization

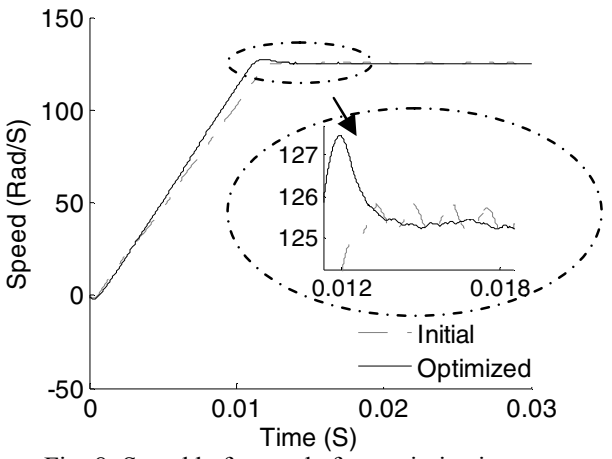

Fig. 8: Speed before and after optimization

Tables II, III, and IV show the initial and the optimal geometries of the IPM motor. As can be concluded from these Tables, there is no need for $A u x_{1}$. The reason is that, this tooth leads to iron saturation in the teeth opening, whereas $A u x_{2}$ which manly influence the back emf waveform as well as cogging torque is properly shaped. Moreover, the volume of copper and magnets before and after optimization are shown in Table V. It is seen that the copper and magnet volume of the optimized machine are reduced. In fact the reduced root mean squared value of current has lead to reduction of area of copper.

Table VI shows a comparison between the performance measures of machine before and after optimization. As can be seen from that almost all of the desired goals were achieved.

TABLE II

STATOR DIMENSION BEFORE AND AFTER OPTIMIZATION (MM)

\begin{tabular}{cccccc}
\hline Stator dimension & $D_{s t}$ & $d_{s}$ & $d$ & $W_{s 2}$ & $W_{s 3}$ \\
\hline Initial & 119.2 & 19.82 & 1.9 & 6.4 & 8.1 \\
\hline Optimized & 117.9 & 18.9 & 1.8 & 6.1 & 7.7 \\
\hline
\end{tabular}

TABLE III

STATOR DIMENSION BEFORE AND AFTER OPTIMIZATION (MM)

\begin{tabular}{cccccc}
\hline $\begin{array}{c}\text { Stator } \\
\text { dimension }\end{array}$ & $R_{r i}$ & $\begin{array}{c}\text { Stack } \\
\text { length }\left(L_{s t}\right)\end{array}$ & Aux $_{1}$ & Aux $_{2}$ & Conductor/slot/phase \\
\hline Initial & 66.54 & 74.5 & 0 & 0 & 17 \\
\hline Optimized & 6.34 & 81 & 0 & 2 & 17 \\
\hline
\end{tabular}

TABLE IV

ROTOR DIMENSION 6 POLE, 2HP, SPM MACHINE (MM)

\begin{tabular}{ccccccc}
\hline Rotor Dimension & $R_{r i}$ & $h_{m}$ & $S_{R}$ & $g$ & $R_{r o}$ & $\alpha$ (degree) \\
\hline Initial & 63.5 & 3 & 14.8 & 3.2 & 66.5 & 0 \\
\hline Optimized & 63.4 & 3.1 & 14.8 & 3.2 & 66.5 & 3.5 \\
\hline
\end{tabular}


TABLE V

VOLUMES AND MASS BEFORE AND AFTER OPTIMIZATION

\begin{tabular}{cccc}
\hline Machine & $\begin{array}{c}\text { Copper } \\
\text { volume in } \\
\text { each slot } \\
\left(\mathrm{cm}^{3}\right)\end{array}$ & $\begin{array}{c}\text { Each } \\
\text { Magnet } \\
\text { pole }\left(\mathrm{cm}^{3}\right)\end{array}$ & Mass $(\mathrm{kg})$ \\
\hline Original & 16.16 & 15.42 & 7.43 \\
\hline Optimized & 15.95 & 14.98 & 8.18 \\
\hline Saved & $\mathbf{0 . 2 1}$ & $\mathbf{0 . 4 4}$ & $\mathbf{0 . 7 5}$ \\
\hline
\end{tabular}

TABLE VI

MACHINE PERFORMANCE BEFORE AND AFTER OPTIMIZATION

\begin{tabular}{ccccccc}
\hline Performances & $T H D(\%)$ & $K_{m}$ & $I_{R M S}$ & $\begin{array}{c}\text { Var } \\
(\omega)\end{array}$ & $\begin{array}{c}R_{a} \\
(\Omega)\end{array}$ & $J\left(A / \mathrm{mm}^{2}\right)$ \\
\hline Initial & 5.1 & 0.889 & 4.61 & 3.5 & 0.807 & 4.84 \\
\hline Optimum & 4.1 & 0.848 & 4.37 & 2.7 & 0.977 & 4.66 \\
\hline
\end{tabular}

\section{DISCUSSION}

By a comparison of the phase current and the back EMF waveforms of the initial and the optimized designs, Figures 9(a) and 9(b), it can be seen that, the current of the optimized machine is visually more close to its back emf. Moreover, by a visual comparison of the current waveform and the back emf waveforms at the vicinity of the peak of the back emf, see Fig. 10 (a) and (b), it is seen that the current is better matched to the back emf in the optimized machine. In fact, the vicinities of the peak of the back emf are where the maximum energy conversions are happened.

Figure 11 (a) and (b) show the phase current waveform of the initial and the optimized machines. As can be seen from this figure, the high order harmonic contents of the initial machine is more than the high order harmonic contents of the optimized machine. In truth, the less high order current harmonics will result in the less magnetic loss in the iron cores, although the magnetic loss was not a direct objective. Furthermore, as mentioned in section (IV.), in the classic design procedure, the current density is assumed three $\left(\mathrm{A} / \mathrm{mm}^{2}\right)$, but as illustrated in table 6 , the current density of the initial machine is calculated as $4.84\left(\mathrm{~A} / \mathrm{mm}^{2}\right)$. In fact, the classic design procedure will not provide the designer will the accurate information about the machine unless the dynamical physics-based model of the machine is calculated and simulated. Here the current density is calculated from the division of the phase current calculated from the physicsbased model and the conductor area in each slots.

This work was performed where some of the geometrical design parameters of the machine were introduce as the optimization variables and the current drive circuit was seen as a black box. Indeed, this is helpful where the machine manufactures needs to make the design of their machines compatible to an existing drives in the market. Indeed, This process is feasible with a real time hardware in loop (HIL) optimization process. From another point of view, for a complete optimization of the motor-drive system both of motor and drive can be optimized together. In this view a low frequency physics-based models of motor-drive systems will be needed.
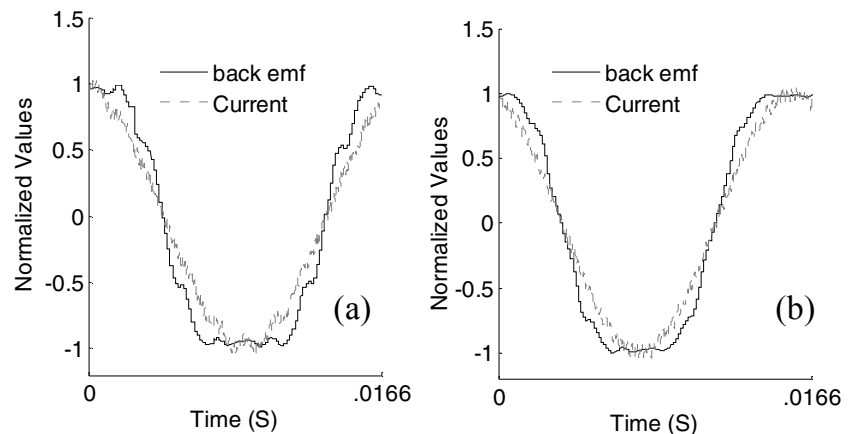

Fig. 9: The current-back emf waveforms before (a) and after optimization (b)
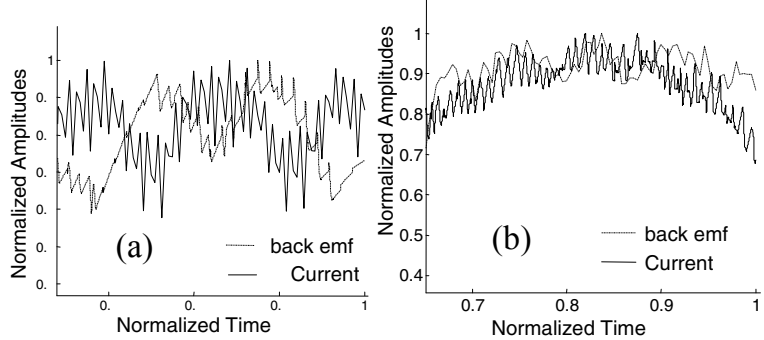

Fig. 10: The current-back emf waveforms at the vicinity of the peak of the back emf before (a) and after optimization (b)
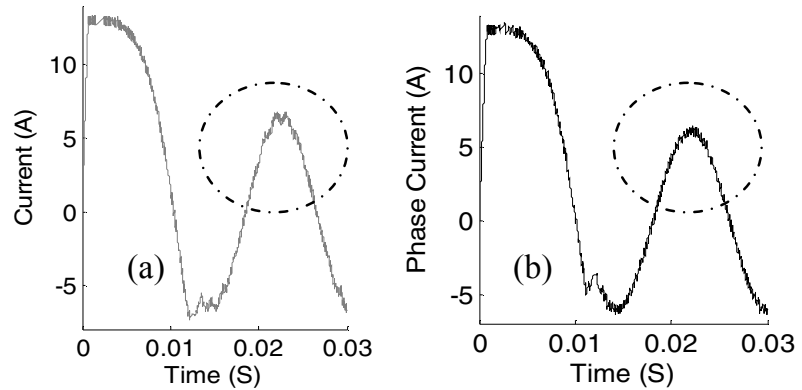

Fig. 11: The Current waveforms before (a) and after optimization (b)

\section{CONCLUSION}

In this paper, the performance enhancement of IPM machine using a hybrid multi-objective optimization of an IPM machine was done where the objectives were calculated from the physics-based model of the machine. A dynamic physics-based phase variable model of the machine, as a fast and accurate model, was used to indirectly link the machine design parameters to its drive circuit during optimization process, in this way, the dynamic effect of PWM IGBT sinusoidal current drive on machine performance during design process was taken into account. After optimization, the area of copper, the area of magnet, the torque ripple, the speed ripple, the total harmonic distortion of the phase currents, the total mass were reduced while the motor constant was increased.

\section{REFERENCES}

[1] Osama A. Mohammed, David A. Lowther, , Meng H. Lean, Bassem Alhalabi , "On the Creation of a Generalized Design Optimization 
Environment for Electromagnetic Devices," IEEE Trans. on magnetics, Vol. 37, No. 5, September 2001

[2] Duane C. Hanselman "Minimum Torque Ripple, Maximum Efficiency Excitation of Brushless Permanent Magnet Motors," IEEE Trans. on Inds. Elec., Vol. 41, No. 3, June 1994.

[3] Duane Hanselman., Brushless Permanent Magnet Motor Design, Second ed. Magna Physic Publishing, 2003, p.p. 108 and 195.

[4] Z. Q. Zhu, Member, IEEE and David Howe "Influence of Design Parameters on Cogging Torque in Permanent Magnet Machines," IEEE Trans. ON Energy Conv., Vol. 15, No. 4, Dec. 2000.

[5] O. A.Mohammed, S. Liu and Z. Liu, "Phase-variable model of PM synchronous machines for integrated motor drives," IEE Proc.-Sci. Meas. Technol., Vol. 151, No. 6, November 2004.

[6] M. Gyimesi, D. Ostergaard, "Inductance computation by incremental finite element analysis," IEEE Trans. On Magnetics, Vol. 35, pp. 11191122, May 1999.

[7] Ali Sarikhani, Ehsan Reihani, Nooshin Nabizadeh, Ali Hooshmand and Moez Davodi, "Analysis of partial discharge by Wavelet-Hilbert transform,"Euro. Trans. Electr. Power, 2008.

[8] Taufik, Yat Tam, and Makbul Anwari, "Comparative study of Sinusoidal Pulse-Width and Hysteresis modulations in Current Source Inverter," International Conference on Intelligent and Advanced Systems, 2007.

[9] Parasopoulos K. E, Vrahatis M. N., "On the Computation of All Global Minimizers through Particle Swarm optimization," IEEE Transaction on Evolutionary Computation, Volume. 8, No. 3, June 2004.

[10] Jarboui B, Damak N, Siarry P, Rebai A. "A combinatorial particle swarm optimization for solving multi-mode resource-constrained project scheduling problems," Applied Mathematics and Computation, vol. 195 299-308, 2008.

[11] Tripathi P.K, Bandyopadhyay S, Pal S.K., "Multi-Objective Particle Swarm Optimization with time variant inertia and acceleration coefficients", Information Sciences, vol. 177, pp. 5033-5049, 2007.

[12] Tan R.R., "Hybrid evolutionary computation for the development of pollution prevention and control strategies," Journal of Cleaner Production, vol. 15, pp. 902-906.

[13] A. Kashefi Kaviani, G.H. Riahy, SH.M. Kouhsari, "Optimal design of a reliable hydrogen-based stand-alone wind/PV generating system, considering component outages," Renewable Energy, Volume 34, Issue 11, Pages 2380-239, November 2009.

[14] Kalyanmoy Deb., Multi-objective optimization using evolutionary algorithms, Wiley press, 2002.

[15] Osama. A. Mohammed, Nagy. Y. Abed "Real-time simulation of electric machine drives with hardware-in-the-loop," COMPEL: The International Journal for Computation and Mathematics in Electrical and Electronic Engineering, Vol. 27 Iss: 4, pp.929 - 938, 2008.

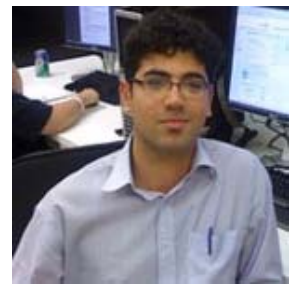

\section{BIOGRAPHIES}

Ali Sarikhani started his bachelor in transmission and distribution engineering in Power and Water University of Technology, Iran. He followed his Master in power electrical engineering in Shahrood University of Technology, Iran. He is now a PHD student of electrical engineering at Energy Systems Research Lab, Florida International University, USA. His current interest is the computer aided design prototyping of electrical apparatus.

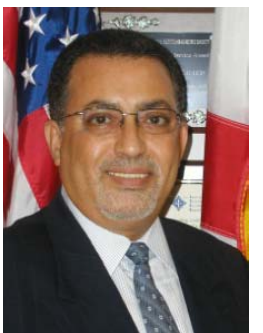

Professor O.A. Mohammed received his M.S. and Ph.D. degrees in Electrical Engineering from Virginia Polytechnic Institute and State University. $\mathrm{He}$ has many years of teaching, curriculum development, research and industrial consulting experience. He authored and co-authored more than 300 technical papers in the archival literature as well as in National and International Conference records in addition to additional numerous technical and project reports and monographs. He is author of book chapters including; Chapter 8 on direct current machines in the Standard Handbook for Electrical Engineers, 15th Edition, McGraw-Hill, 2007 and a book Chapter entitled " Optimal Design of Magnetostatic Devices: the genetic Algorithm Approach and System Optimization Strategies," in the Book entitled: Electromagnetic Optimization by Genetic Algorithms, John Wiley \& Sons, 1999.

Professor Mohammed specializes in Electrical Energy Systems especially in areas related to alternate and renewable energy systems. He is also interested in design optimization of electromagnetic devices, Artificial Intelligence Applications to Energy Systems as well as Electromagnetic Field Computations in Nonlinear Systems for these energy applications. He has current interest in Shipboard power systems and integrated motor drives. He is also interested in the application communication and sensor networks for the distributed control of power grids. Dr. Mohammed has been successful in obtaining a number of research contracts and grants from industries and Federal government agencies. He has a current active and funded research programs in several areas funded by the office of Naval Research and the US Department of Energy. Professor Mohammed is also interested in developing learning environments and educational techniques for Internet based delivery systems and virtual laboratories.

Professor Mohammed is a Fellow of IEEE and is a Fellow of the Applied Computational Electromagnetic Society. He is Editor of IEEE Transactions on Energy Conversion, IEEE Transactions on Magnetics, Power Engineering Letters and also an Editor of COMPEL. Professor Mohammed is the current President of the Applied Computational Electromagnetic Society (ACES).

He received many awards for excellence in research, teaching and service to the profession. Professor Mohammed has chaired sessions and programs in numerous International Conferences and has delivered numerous invited lectures at scientific organizations in North and South America, Europe, Asia and Africa. Professor Mohammed was the General Chair of the 2009 IEEE IEMDC conference held in Miami Florida, May 3-6 2009 and was the Editorial Board Chairman for the IEEE CEFC2010 held in Chicago, IL USA, May 9-12, 2010. Professor Mohammed was also the general chair of the IEEE CEFC 2006 held in Miami, Florida, April 30 - May 3, 2006. He was also general chair of the 19th annual Conference of the Applied Computational Electromagnetic Society ACES-2006 held in Miami, Florida March 14-17, 2006. He was the General Chairman of the 1993 COMPUMAG International Conference and was also the General Chairman of the 1996 IEEE International Conference on Intelligent Systems Applications to Power Systems (ISAP'96) as well as the General Chairman of the 1994 IEEE Southeast conference. He was the technical program chair for the IEEE CEFC conference in Milwaukee, WI, June, 2000 and was the Publications Chair for the IEEE conference on Nanoscale Devices and System Integration, IEEE-NDSI 2004, Miami, FL February 15-19, 2004. Dr. Mohammed also organized and taught many short courses on power systems, Electromagnetics and intelligent systems in the U.S.A and abroad. 